\title{
Comparison of wind measurements in the troposphere and mesosphere by VHF/MF radars and in-situ techniques
}

\author{
N. Engler, W. Singer, R. Latteck, and B. Strelnikov \\ Leibniz Inst. of Atmospheric Physics Kühlungsborn at Univ. of Rostock e.V., Schlossstr. 6, 18225 Kühlungsborn, Germany
}

Received: 7 November 2007 - Revised: 10 July 2008 - Accepted: 8 October 2008 - Published: 24 November 2008

\begin{abstract}
Radar wind observations at frequencies between 1.98 and $53.5 \mathrm{MHz}$ obtained at polar latitudes were compared to in-situ wind measurements by radiosondes at tropospheric altitudes and to winds from falling spheres at mesospheric altitudes. Comparisons are shown for several campaigns of radiosonde and falling sphere observations. The radar wind directions agree well to the radiosonde and falling sphere observations and are highly correlated. The winds estimated from radar measurements are less than the radiosonde data by about $15 \%$ for spaced antenna observations and by about $10 \%$ for the Doppler beam swinging experiment. At mesospheric altitudes the spaced antenna winds obtained from the wide-beam Andenes MF radar are underestimated in the order of $35 \%$ and winds from the narrow-beam Saura MF radar are underestimated by about $20 \%$ compared to falling sphere winds at altitudes between 70 and $80 \mathrm{~km}$. Furthermore, the relation between wind measurements using narrow-beam and wide-beam antenna arrangements for the MF radars is discussed and VHF radar observations are compared to the wide-beam MF radar.
\end{abstract}

Keywords. Meteorology and atmospheric dynamics (Middle atmosphere dynamics; Instruments and techniques)

\section{Introduction}

Radar sounding observations of the lower and middle atmosphere have been conducted continuously at Andenes, Northern Norway $\left(69^{\circ} \mathrm{N}, 16^{\circ} \mathrm{E}\right)$, since 1998 . Four radars have been installed near the Arctic Lidar Observatory for Middle Atmosphere Research (ALOMAR) and the Andøya Rocket Range operating at frequencies between $1.98 \mathrm{MHz}$ and 53.5 MHz. The combination of ground-based, balloon, and rocket-borne instruments enables an unique opportu-

Correspondence to: N. Engler

(engler@iap-kborn.de) nity for the investigation of winds at tropospheric and mesospheric altitudes.

The determination of horizontal winds by means of atmospheric radar techniques is based on the motion of scattering atmospheric structures through the radar beam. Using the Doppler beam swinging method (DBS) the threedimensional wind field can be estimated from the Doppler shift of the backscattered radio waves evaluating vertical and off-zenith beam pointing directions. Another approach relates the horizontal drift of the diffraction pattern of illuminated refractive index variations on the ground to the horizontal winds by cross-correlating the backscattered signals of at least 3 spatially separated receivers. A detailed description of this spaced antenna technique (SA) was given by Briggs (1984) and is widely used in current radar installations (e.g. Singer et al., 1997; Latteck et al., 1999; Singer et al., 2003b). Since there are some differences in the design of the experiments Sect. 2 introduces the instruments and methods in more detail.

Tropospheric winds were observed in the past by several groups and compared to radiosonde wind measurements (e.g. Röttger et al., 1981; Kato et al., 1986; Vincent et al., 1987; Hocking, 1997; Luce et al., 2001). Statistical comparisons of several radiosonde observations to UHF wind profiler were performed by Weber and Wuertz (1990) as well as to VHF radar measurements by Thomas et al. (1997) taking into account the influence of aspect sensitive backscatter in the analysis. Wind observations at mesospheric altitudes have been used for several comparisons between radars at different frequencies and meteorological rockets (e.g. Vincent et al., 1977; Lübken et al., 1990; Manson et al., 1992; Müllemann and Lübken, 2005). Winds derived from different radar methods were compared to each other in the literature (e.g. Reid, 1988; Manson et al., 1992; Venkat Ratnam et al., 2001; Thayaparan and Hocking, 2002; Holdsworth and Reid, 2004a,b; Hall et al., 2005). Furthermore, radar wind measurements were compared to optical methods (e.g. Meek

Published by Copernicus Publications on behalf of the European Geosciences Union. 
Table 1. Experimental parameters of the radars located at Andenes $\left(69^{\circ} \mathrm{N}, 16^{\circ} \mathrm{E}\right)$.

\begin{tabular}{lllll}
\hline Parameter & $\begin{array}{l}\text { Andenes MF radar } \\
(\text { AMF })\end{array}$ & $\begin{array}{l}\text { Saura MF radar } \\
(\text { SMF })\end{array}$ & $\begin{array}{l}\text { SKiYMET radar } \\
\text { (Met) }\end{array}$ & $\begin{array}{l}\text { ALWIN MST radar } \\
(\text { VHF })\end{array}$ \\
\hline Frequency & $1.98 \mathrm{MHz}$ & $3.17 \mathrm{MHz}$ & $32.55 \mathrm{MHz}$ & $53.5 \mathrm{MHz}$ \\
Peak power & $40 \mathrm{~kW}$ & $116 \mathrm{~kW}$ & $12 \mathrm{~kW}$ & $36 \mathrm{~kW}$ \\
Pulse repetition (day/night) & $80 / 40 \mathrm{~Hz}$ & $80 / 80 \mathrm{~Hz}$ & $2144 \mathrm{~Hz}$ & $5000 \mathrm{~Hz} / 1250 \mathrm{~Hz}(\mathrm{Tropo} / \mathrm{Meso})$ \\
Altitude range & $50-100 \mathrm{~km}$ & $50-100 \mathrm{~km}$ & $82-110 \mathrm{~km}$ & $1-18 \mathrm{~km} / 50-114 \mathrm{~km}(\mathrm{Tropo} / \mathrm{Meso})$ \\
Pulse width & $4 \mathrm{~km}$ & $1 \mathrm{~km}$ & $2 \mathrm{~km}$ & $600 \mathrm{~m} / 300 \mathrm{~m}(\mathrm{Tropo} / \mathrm{Meso})$ \\
Sampling resolution & $2 \mathrm{~km}$ & $1 \mathrm{~km}$ & $2 \mathrm{~km}$ & $300 \mathrm{~m}$ \\
Experiment & $\mathrm{SA}$ & $\mathrm{SA}, \mathrm{DBS}$ & Meteor & $\mathrm{SA}, \mathrm{DBS}$ \\
2-way 1/e half-beamwidth (SA/DBS) & $29.4^{\circ} /-$ & $4.8^{\circ} / 2.6^{\circ}$ & N/A & $4.4^{\circ} / 2.6^{\circ}$ \\
\hline
\end{tabular}

et al., 1997; Franke et al., 2001; Salah et al., 1999; Clark et al., 1999; Liu et al., 2002) or to satellite wind estimates on UARS (e.g. Burrage et al., 1996; Meek et al., 1997).

The current study concentrates on the evaluation of the observed wind parameters by radars with in-situ techniques. At tropospheric altitudes the launch of radiosondes is an appropriate tool for the observation of winds, temperature, and pressure. Therefore, at all 110 simultaneous wind profiles were selected for the comparison with the SA observations and 186 simultaneous profiles with DBS measurements for the period between 2004 and 2007. The results and statistical analyses are presented in Sect. 3.1. The wind field at mesospheric altitudes was investigated by falling spheres which were launched from the co-located Andøya Rocket Range (Müllemann and Lübken, 2005). At all, 46 height profiles were used for the comparison of falling sphere winds to radar wind estimates during the period between 1999 and 2005 . Radar winds were estimated with two medium-frequency (MF) radars at the Andøya island for the launch periods and presented in Sect. 3.2. Additionally, a comparison between MF and VHF radars was prepared for a selected period during July 2003. A direct comparison of VHF radar winds to falling spheres is not possible because there were only very few measurements in the same altitude range available. A similar comparison is performed for meteor radar winds to MF radar winds for the overlapping altitude region of both experiments between 82 and $86 \mathrm{~km}$ (Sect. 3.3).

\section{Experiments}

For this study wind measurements were gathered from the ALWIN MST radar using spaced-antenna (SA) and Doppler beam swinging (DBS) experiments at tropospheric altitudes. The VHF radar started operation in 1998 for the investigation of tropospheric dynamics and also of strong radar echoes from the mesopause region (Latteck et al., 1999). Table 1 summarizes the experimental parameters of this radar in comparison to the other instruments. The twoway $1 / e$ half-beamwidth parameter shows the differences in the beamwidth of the methods used in the experiments of this comparison. Using the SA method the returned signals were analyzed using the full-correlation analysis (FCA) after Briggs (1984). The DBS analysis removes spectral contaminants and considers finite beamwidth, finite pulse length as well as the beam and shear broadening of the spectrum, as discussed by Hocking (1983a,b).

In order to select undisturbed radar echoes several criteria were chosen for the evaluation of the data. Therefore, only profiles which were not infected by external interferences were selected and where the horizontal and the vertical wind speeds do not exceed certain thresholds $\left(120 \mathrm{~m} \mathrm{~s}^{-1}\right.$ and $6 \mathrm{~m} \mathrm{~s}^{-1}$, respectively). Furthermore, the signal-to-noise ratio has to exceed a threshold of $3 \mathrm{~dB}$ so that only reliable data were considered.

The tropospheric winds deduced from the ALWIN MST radar were compared to winds from radiosondes launched at the co-located radiosonde station. For a comparison of simultaneous wind profiles, hourly median values were prepared starting at the launch times of the radiosondes. Assuming that the background wind does not change drastically during this particular hour, the hourly median winds are a good approximation. The radiosonde height profiles were smoothed in order to obtain a height resolution comparable to the radar wind measurements which is $300 \mathrm{~m}$ for SA and $600 \mathrm{~m}$ for DBS. Figure 1 shows a typical vertical height profile of a radiosonde launch during the ROMA-LEWIZ winter campaign conducted at Andenes in January 2005 in comparison to radar observations. Radiosondes can measure winds with an accuracy of $0.15 \mathrm{~m} \mathrm{~s}^{-1}$. An uncertainty of the radar wind measurement was determined to be less than $2 \mathrm{~m} \mathrm{~s}^{-1}$ for the averaging period of one hour.

Mesospheric winds were obtained from the wide-beam Andenes MF radar (AMF) and the narrow-beam Saura MF radar (SMF) using the SA technique (Singer et al., 1997, 2003b, 2008). Wind estimations from the MF radars are available between 70 and $90 \mathrm{~km}$. These radar wind measurements were compared to falling spheres launched by meteorological rockets during several campaigns conducted at the Andøya Rocket Range near Andenes (Müllemann, 2004). The falling spheres normally inflate in a distance of about 

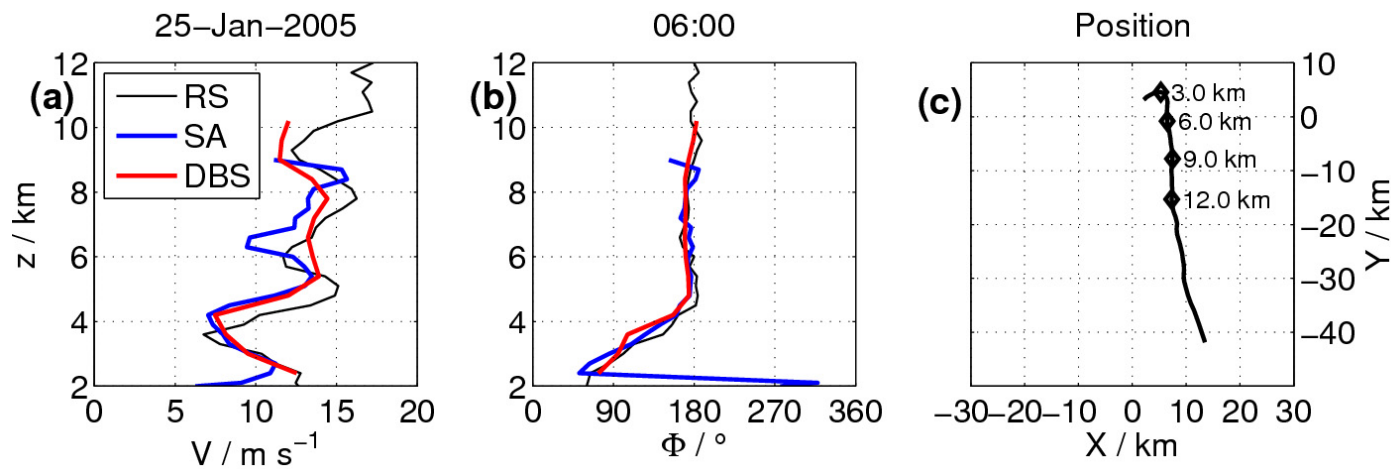

Fig. 1. Comparison of typical height profiles from radiosonde (RS) and radar soundings (DBS and SA). Wind speed (a) and wind direction (b) are shown for the three methods as well as the trajectory of the radiosonde (c) which shows the distance to the ALWIN VHF radar.

$60 \mathrm{~km}$ away from the radar site in an altitude above $100 \mathrm{~km}$. After inflation the spheres descent with a high velocity and data were collected with a sample period of $0.3 \mathrm{~s}$. The height resolution of a measurement with a falling sphere is determined by the height and density dependent reaction time on density fluctuations. The recorded trajectory of the sphere is fitted in height intervals by Legendre polynoms in order to determine the velocity and acceleration of a falling sphere. The filtering due to the interval length and degree of the Legendre polynom provide the lower limit in the resolution of structures in the atmosphere. Above $80 \mathrm{~km}$ the interval length in the vertical direction is about $10 \mathrm{~km}$ where structures down to a vertical extension of $5 \mathrm{~km}$ (half of the interval length) can be detected and between 70 and $80 \mathrm{~km}$ the interval length is $6 \mathrm{~km}$ (Müllemann, 2004). In case of a general selection criteria for the wind measurements by falling spheres only values were accepted where the downward velocity of the sphere was less than 1.75 Mach. Note, this criterion is mostly true for falling sphere measurements below $80 \mathrm{~km}$.

A comparison of the mesospheric winds obtained from the ALWIN VHF radar directly to falling sphere winds is not possible for different reasons. The period of wind determination by VHF radars is limited to the occurrence of polar mesosphere summer echoes (PMSE) which generally occur at altitudes between 80 and $90 \mathrm{~km}$. Since most of the falling spheres provide reliable wind estimates only below $80 \mathrm{~km}$ another approach for a comparison was used in this study. In a coarse approach VHF wind measurements were compared to the wide-beam AMF radar winds which are continuously available in July 2003. In order to achieve a comparable height resolution the VHF radar wind values were averaged in $2 \mathrm{~km}$ bins over an altitude range of $4 \mathrm{~km}$.

The SKiYMET meteor radar is co-located to the ALWIN MST radar since 2001. The meteor trail is located with a range resolution of $2 \mathrm{~km}$ and an angular resolution of $1-2^{\circ}$ using a 5-antenna interferometer allowing height-resolved wind measurements (Hocking et al., 2001; Singer et al., 2003a). In order to estimate the hourly mean winds only meteor detections with zenith angles less than $60^{\circ}$ were used and at least 10 meteor detections per height bin. The meteors for the wind estimation are binned into height intervals of $3 \mathrm{~km}$. A direct comparison to falling spheres is not possible since the altitude range of meteor detections is above the altitude range of reliable falling sphere winds. Hence, comparisons of winds obtained in a common volume by the AMF radar, the meteor radar, and the ALWIN VHF radar were performed.

\section{Results}

3.1 Comparison of radar and radiosonde winds at tropospheric altitudes

The ALWIN MST radar is continuously operated in tropospheric mode. During the period 2004-2007 simultaneous observations of radiosonde and radar winds were selected and an example of a launch during the ROMA-LEWIZ campaign in January 2005 is shown in Fig. 1. The wind speeds derived from the SA and DBS experiments are in good agreement to the radiosonde estimates for the whole altitude range between 2 and $12 \mathrm{~km}$ as displayed in panel (a) of Fig. 1 . Some differences of the hourly median estimates occur in the observations which were due to the variability of the atmosphere on short time scales during the averaging period. The directions given in degree east of north in panel (b) agree well for the three methods. It is proved by the movement of the radiosonde analyzing the trajectory as presented in Fig. 1c. The distance of the balloon to the radar site is about $7 \mathrm{~km}$ southward at $8 \mathrm{~km}$ altitude. Furthermore, between 4 and $12 \mathrm{~km}$ the radiosonde is transported southwards which corresponds to the horizontal wind direction obtained from the different methods.

The variation of the difference between radar wind speed and radiosonde wind speed in dependence of the flight 

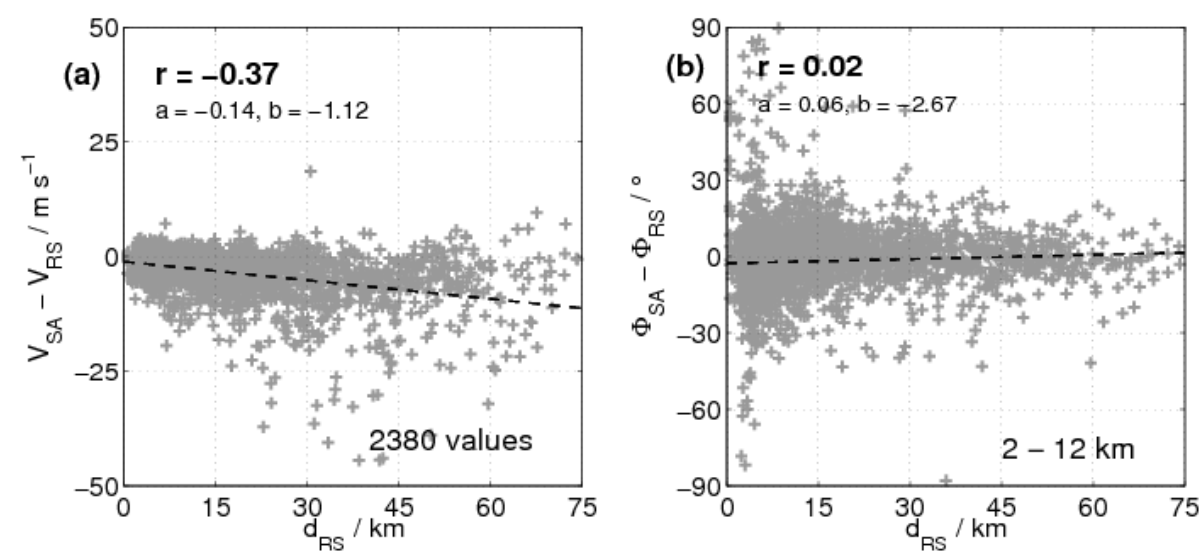

Fig. 2. Scatter plots (SA wind minus radiosonde wind measurements) of wind speed (a) and wind direction (b) between 2 and $12 \mathrm{~km}$ depending on the distance between radiosonde and radar for all radiosonde launches in 2004-2007.
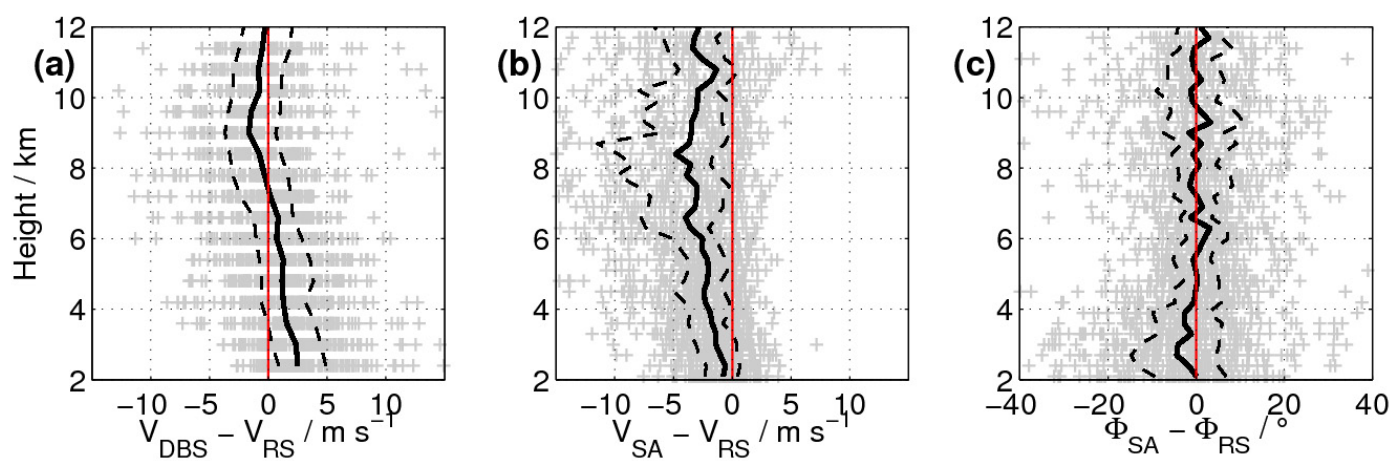

Fig. 3. Differences of wind speed obtained from Doppler experiment (a), spaced antenna wind speed (b), and direction (c) between the ALWIN VHF radar and radiosondes (crosses). The solid line represents the median height profile for all simultaneous measurements and the dashed lines the quartiles.

distance of the radiosonde is shown as scatter plot in Fig. 2a. An anti-correlation was found for the observed altitudes between 2 and $12 \mathrm{~km}$ with a correlation coefficient determined to $r=-0.37$. The difference between radar and radiosonde winds increases with increasing distance which was also found during the MUTSI campaign (Luce et al., 2001). This is an effect of the inhomogeneous wind field because processes on short time scales influence the dynamics of the atmosphere. The direction differences did not correlate with the distance of the radiosondes as shown in Fig. 2b. The variations are in the order of $\pm 30^{\circ}$ for short distances and the slope of the linear regression is nearly zero.

The height variation of the differences between radar and radiosonde winds is presented on the basis of hourly median winds in Fig. 3.The solid line represents the median profile for all available values and the dashed lines are the lower and upper quartiles. The horizontal wind velocities from the DBS fit well to that from the radiosondes where the median speed below $7 \mathrm{~km}$ is slightly larger for the radar measurement. The median wind speed of the SA experiment is underestimated of about $2-5 \mathrm{~m} \mathrm{~s}^{-1}$ for all ranges. Figure $3 \mathrm{c}$ shows the differences of the wind directions between the SA method and the radiosondes with medians close to zero at all ranges. The observations vary obviously due to geographical and instrumental reasons. The radar is located at a fixed point and is operated in the tropospheric mode with a height resolution of $600 \mathrm{~m}$ sampled in $300 \mathrm{~m}$ bins. Hourly median wind profiles were prepared which are an average observation during the flight of the radiosonde. After launching the radiosonde the balloon is transported by the wind for a certain distance away from the radar site as shown in Fig. 1c. The wind characteristics change during the observational period and introduce differences in the observations. Furthermore, the balloons were also influenced by small-scale structures and variations of the local wind field.

Scatter plots of radar and radiosonde winds for the altitude range between 2 and $8 \mathrm{~km}$ are shown in Fig. 4. SA winds are not biased by low Signal-to-Noise ratios at these 

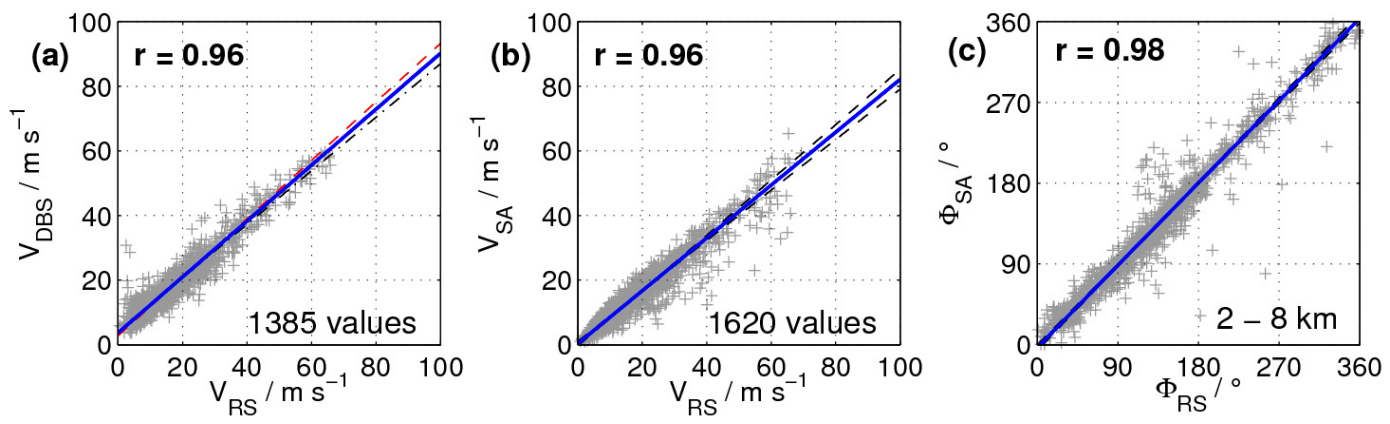

Fig. 4. Scatter plots of wind speed obtained from Doppler experiment (a), spaced antenna wind speed (b) and direction (c) for the ALWIN VHF radar and radiosondes for the altitude range between 2 and $8 \mathrm{~km}$. The crosses mark the hourly median values, the lines are correlations concerning that both variables have errors.

altitudes. Wind speeds measured by DBS (a) and SA (b) are well correlated but are underestimated by about $10 \%$ for DBS and 15\% for SA compared to the radiosonde speed measurements. The wind directions obtained from SA and radiosonde observations agreed very well as shown in Fig. 4c and as also shown by the high correlation coefficients.

The result of the DBS measurement is similar to the observation by Hocking (1997) who found an underestimation of DBS wind speed in the order of $10 \%$ for the altitude range between 2 and $8 \mathrm{~km}$. The correlation coefficients are in the same order as given by Hocking (1997), $r=0.96$ vs. $r=0.92$ for wind speeds and $r=0.98$ vs. $r=0.97$ for wind directions. The comparison between radiosondes and the two modes of radar observation shows that there is a clear difference between the SA and the DBS method. The smaller beamwidth on reception of the Doppler experiment and the direct measurement of the radial wind components are probably an advantage to the spaced antenna experiment using the full-correlation analysis (FCA, Briggs, 1984). The aspect sensitivity of the scattering entities can influence the estimation of the wind velocities in the Doppler experiments (Hocking, 1989, 1997). For the Doppler analysis the narrow radar beam is tilted $7^{\circ}$ off-zenith for wind measurements and the influence of aspect sensitive backscatter has been considered in the wind analysis. In the SA experiment the narrow transmitted beam is pointed towards the zenith but the widebeam receiving antennas collect signals from a wider area. These signals can be influenced by e.g. high-frequency gravity waves (Meek and Reid, 1989; Hocking, 1988; Vandepeer and Hocking, 1993) or the triangle size effect (Holdsworth, 1999).

In order to compare the results to previous investigations the bias of the wind estimates and the rms differences were determined. These error estimates are summarized in Table 2. For the SA wind comparison to radiosondes a bias of $-2.9 \mathrm{~m} \mathrm{~s}^{-1}$ was determined for the wind speed and $-0.5^{\circ}$ for the direction. The rms differences were estimated to $5.0 \mathrm{~m} \mathrm{~s}^{-1}$ and $16.6^{\circ}$ for speed and direction, respectively.
Table 2. Comparison of winds obtained from spaced antenna (SA) and Doppler beam swinging (DBS) methods of the ALWIN VHF radar and radiosonde measurements in the altitude range between 2 and $8 \mathrm{~km}$ (bias, standard deviation, and rms differences).

\begin{tabular}{lcccc}
\hline & & bias & std & rms \\
\hline SA - RS & $V$ & $-2.9 \mathrm{~m} \mathrm{~s}^{-1}$ & $4.0 \mathrm{~m} \mathrm{~s}^{-1}$ & $5.0 \mathrm{~m} \mathrm{~s}^{-1}$ \\
& $\Phi$ & $-0.5^{\circ}$ & $16.6^{\circ}$ & $16.6^{\circ}$ \\
DBS - RS & $V$ & $-1.1 \mathrm{~m} \mathrm{~s}^{-1}$ & $3.6 \mathrm{~m} \mathrm{~s}^{-1}$ & $3.8 \mathrm{~m} \mathrm{~s}^{-1}$ \\
& $\Phi$ & $-1.6^{\circ}$ & $16.5^{\circ}$ & $16.5^{\circ}$ \\
\hline
\end{tabular}

These values are in the same order of magnitude compared to studies by Vincent et al. (1987), 5-7 $\mathrm{m} \mathrm{s}^{-1}$ and $10-15^{\circ}$, and Weber and Wuertz (1990). The estimates of biases and rms errors for both methods, SA and DBS, are shown in Table 2.

\subsection{Comparison of radar and falling sphere winds at meso- spheric altitudes}

At the radar site in Northern Norway continuous wind measurements at mesospheric altitudes are available for several years. The rocket launch area nearby provides a unique opportunity to compare the radar measurements to winds from falling spheres launched by meteorological rockets. The measurements compared here are not really common volume observations but the locations are close together. This allows the comparison of radar winds to in-situ estimates which have a similar altitude resolution between 70 and $80 \mathrm{~km}$. Scatter plots of radar winds and of winds from 46 falling sphere launches from altitudes between 70 and approximately $80 \mathrm{~km}$ are shown in Fig. 5. The wide-beam Andenes MF radar receives echoes from a large volume which is defined by the transmitting beamwidth of $60^{\circ}$ and the pulse width of $4 \mathrm{~km}$. The winds derived from the falling spheres were estimated by fitting a Legendre polynom to the trajectory data with an interval length of $6 \mathrm{~km}$ in the vertical 

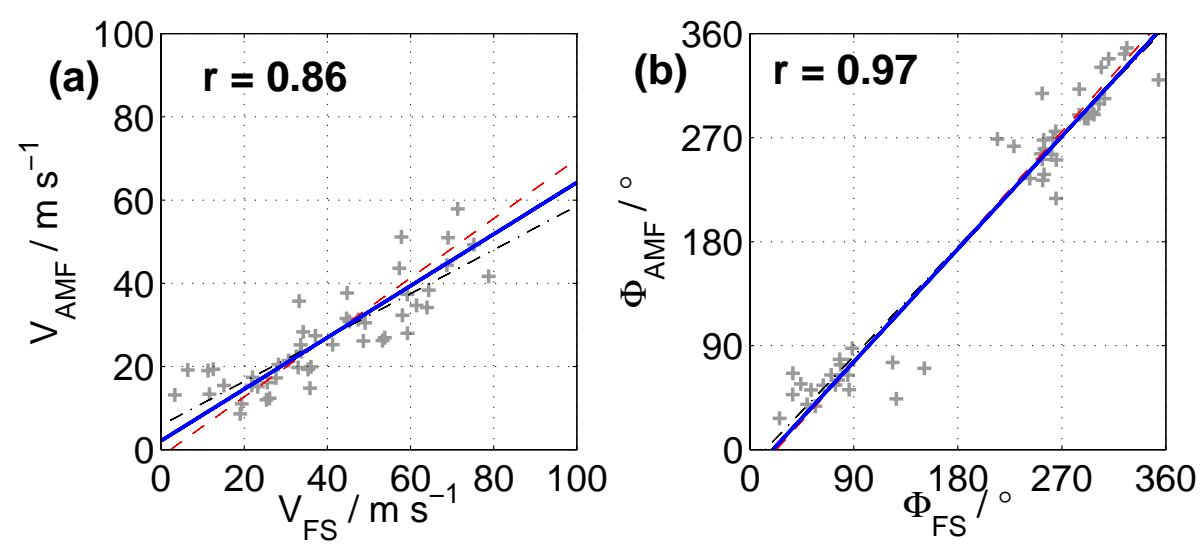

Fig. 5. Scatter plots of wind speed (a) and direction (b) from the spaced antenna experiment using the wide-beam Andenes MF radar $\left(V_{\mathrm{AMF}}, \Phi_{\mathrm{AMF}}\right)$ and falling spheres $\left(V_{\mathrm{FS}}, \Phi_{\mathrm{FS}}\right)$ for the altitude range below $80 \mathrm{~km}$.
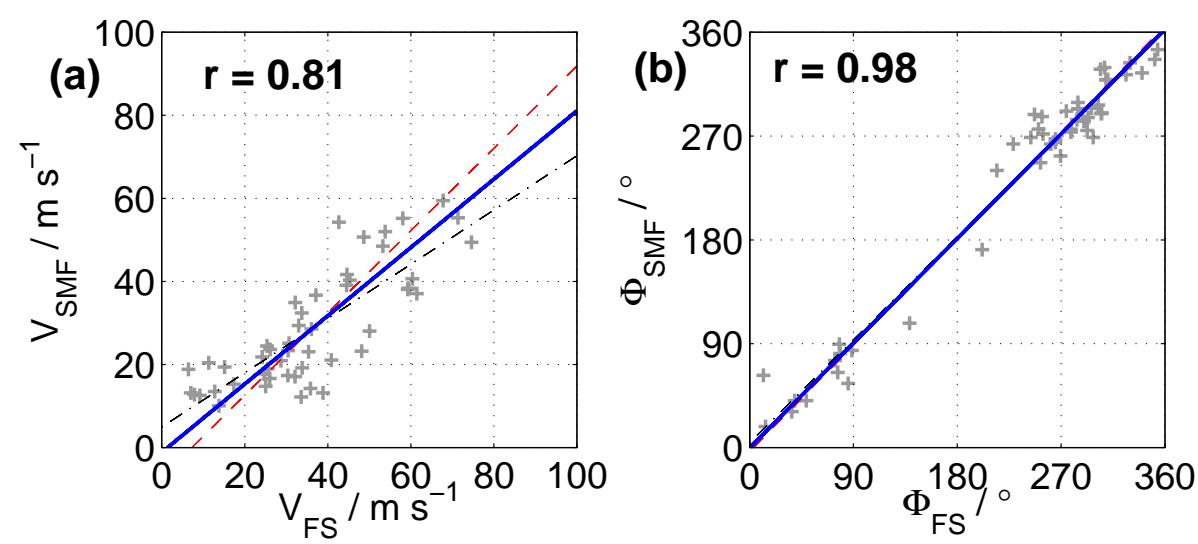

Fig. 6. Scatter plots of wind speed (a) and direction (b) from the spaced antenna experiment using the narrow-beam Saura MF radar $\left(V_{\mathrm{SMF}}, \Phi_{\mathrm{SMF}}\right)$ and falling spheres $\left(V_{\mathrm{FS}}, \Phi_{\mathrm{FS}}\right)$ for the altitude range below $80 \mathrm{~km}$.

direction. The height resolutions of the two methods are comparable.

The wind speed shown in Fig. 5a is in the order of $35 \%$ less than the wind speed estimated from the falling spheres. This result is in good agreement to previous wind comparisons by Manson et al. (1992). The wind directions agree well comparing the wide-beam AMF radar data to falling spheres (Fig. 5b). Observations during all seasons are available and were compiled in this figure. This is clearly seen in Fig. 5b because during polar summer easterly winds are predominant whereas during polar winter westerly winds are observed at mesospheric altitudes.

The Saura MF radar has improved characteristics using a narrow transmitting beam with the half-power fullwidth of $6^{\circ}$ and the receiving antennas are arranged as an "Y". Figure 6 shows the results of the SA experiment compared to falling sphere wind estimations. The wind speed is still underestimated by the radar observation in the order of $20 \%$ but the values correlate better than the values obtained from the wide-beam AMF radar. This is understandable as the illuminated scattering volume is much smaller due to the narrow transmitting beam and a pulse length of $1 \mathrm{~km}$ which provides an increased altitude resolution. On the other hand, the wide-beam AMF radar estimates can be contaminated by vertical fluctuating motions due to waves (Hocking, 1988) and high-frequency gravity waves (Vandepeer and Hocking, 1993). The DBS capability of this radar was not available at that time.

Earlier observations of mesospheric winds by means of rockets and radars operated at different frequencies were discussed in several publications (e.g. Meek and Manson, 1985; Lübken et al., 1990; Murayama et al., 1999). It was found that MF radar winds are in mean about $20 \%$ smaller than winds observed by rockets (Meek and Manson, 1985) and similar results were shown by Lübken et al. (1990). The results observed in the current study are comparable to the 

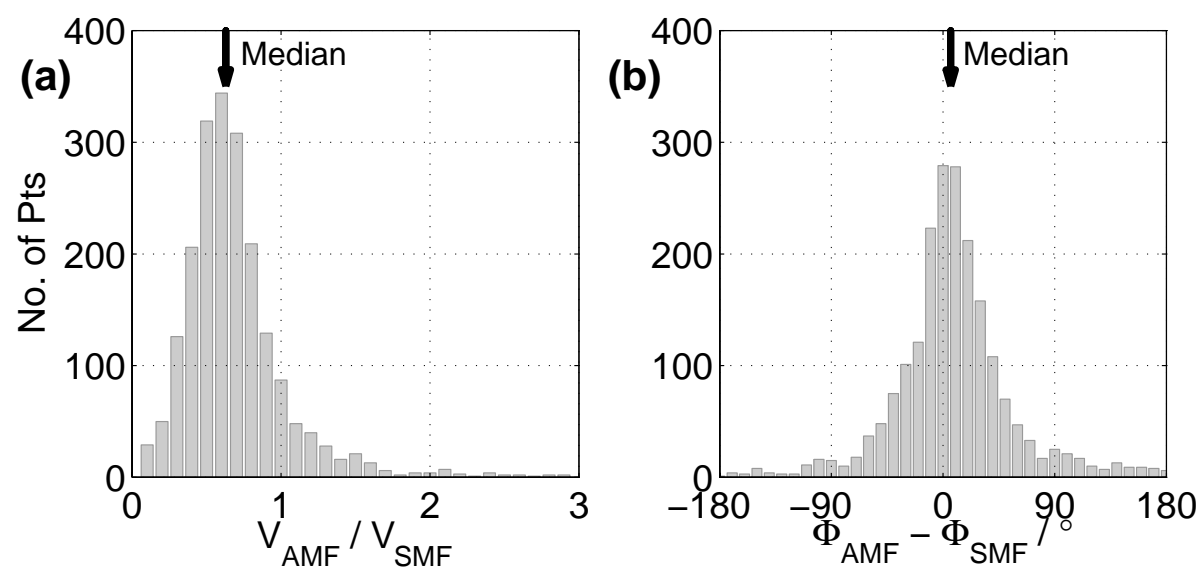

Fig. 7. Histogram of the ratios of the wind speeds (a) and differences of the wind directions (b) between Andenes MF and Saura MF radars in the altitude range of 82 and $86 \mathrm{~km}$ (July 2003).

earlier investigations. The wide-beam MF radar (AMF) underestimates the wind speed in the overlapping altitude region in the order of 35\% which is given by Meek and Manson (1985) as upper limit for summer observations at $88 \mathrm{~km}$. The observed differences between radar winds and in-situ measurements from falling spheres are mostly related to the different sampling methods - the falling sphere data are averaged in height whereas the MF radar winds are averaged over the pulse volume. In addition, spatial inhomogeneities of the wind field contribute to the observed differences.

\subsection{Comparison of radar winds at mesospheric altitudes}

In this comparison one month in summer 2003 was selected because data of several radars were available for this period. Hourly median wind values were prepared for July 2003, a period during the occurrence of polar mesosphere summer echoes (PMSE) in VHF radar observations. The comparison of the ratios of the wind speeds and the differences of the wind directions between the AMF and the SMF radars is shown as a frequency distribution in Fig. 7. The ratios of the wind speed estimates indicate that the values of the wide-beam AMF radar are in the order of one-third smaller than the wind speeds of the narrow-beam SMF radar. In Fig. $7 \mathrm{~b}$ the distribution of differences in the wind directions is shown. The directions agree well for the comparison between both radars and the median is nearly zero. In order to compare the results to other observations the rms differences were determined for these observations, $15.5 \mathrm{~m} \mathrm{~s}^{-1}$ for the wind speed and $6.9^{\circ}$ for the wind direction.

In order to study possible reasons for the differences in the wind speeds observed by the two MF radars additional parameters were investigated. One important point, which has to be considered, is the influence of the angular variation of the backscattered echoes also known as aspect sensitivity (Röttger, 1981; Reid, 1990). The aspect sensitivity param- eter, $\theta_{s}$, was determined after the relation for the "spacial correlation" given by Lesicar and Hocking (1992) which includes the axial ratio and the pattern scale of the correlation ellipse (see also Appendix B for details). The aspect sensitivity is a quantitative explanation for the isotropic/anisotropic shape of the scatterers where small values of $\theta_{s}$ describe a high aspect sensitivity and, therefore, a high degree of anisotropy.

Figure 8a shows the frequency distribution in the aspect angle differences between the two MF radar experiments. The shape of the distribution is asymmetric and will not be discussed here in more detail. The median is nearly zero but the distribution shows a maximum peak at differences around $1^{\circ}$. This result indicates that the aspect sensitivity observed by the wide-beam AMF radar is smaller (larger $\theta_{s}$ ) at the maximum peak than that observed with the narrowbeam SMF radar. Due to the large volume illuminated by the AMF radar the backscatter from different scattering angles contribute to the diffraction pattern received by the spaced antennas. In observations with the narrow-beam SMF radar backscatter from a small volume illuminated near the zenith contribute with smaller aspect angles. This is related to more anisotropic scatterers. But there are numerous values where the aspect sensitivity of the narrow-beam SMF radar is lower (larger $\theta_{s}$ ) than that observed with the wide-beam AMF radar. The wide-beam AMF radar will also collect echoes from structures at larger off-zenith angles where the ground diffraction pattern could be influenced by variations in the wind field with height, by wind field inhomogeneities because of gravity waves, or by short period gravity waves (Holdsworth et al., 2001, and references therein). The influence of gravity waves and the discussion whether a partial reflection radar measures the true velocity of wind or the phase velocity of gravity waves was initiated by Hines et al. (1993) on the basis of numerous experimental results. However, 

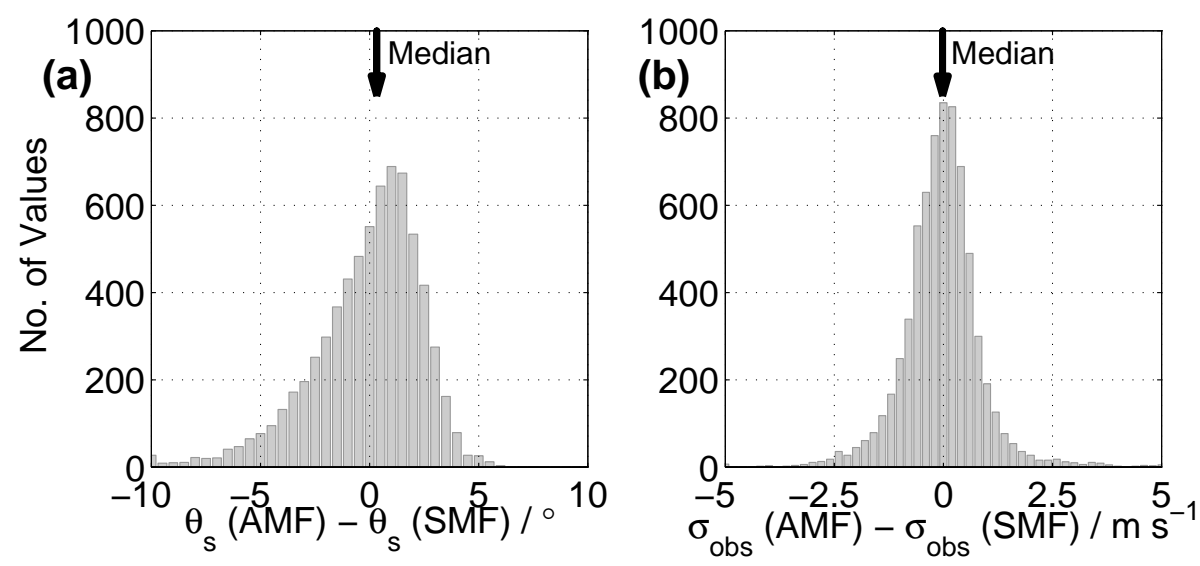

Fig. 8. Histogram of differences of the aspect sensitivity parameter (a) and the spectral width (b) between Andenes MF and Saura MF radars in the altitude range of 82 and $86 \mathrm{~km}$ during July 2003.
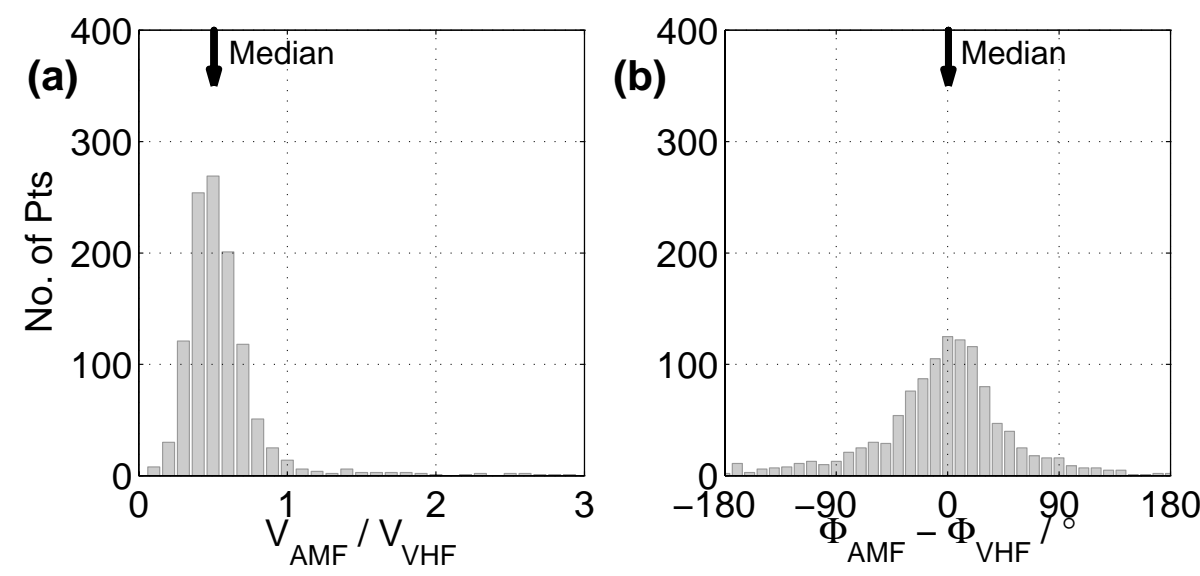

Fig. 9. Histogram of the ratios of the wind speeds (a) and differences of the wind directions (b) between Andenes MF and ALWIN VHF radars in the altitude range of 82 and $86 \mathrm{~km}$ (July 2003).

from our observations the influence of the transmitted beam width can be extracted as the predominant reason of lower wind speeds observed by the wide-beam AMF radar.

Additionally, the spectral width obtained from the pattern lifetime of the correlation analysis (see Appendix B) is shown in Fig. 8b. The velocity distribution is nearly identical and the median value of the distribution is zero. These observations show that the influence of spectral broadening might play a minor role in the differences of the wind speed observations.

For the VHF radar winds a direct comparison to falling spheres is not possible at mesospheric altitudes due to the different height coverage of the methods. Therefore, a rough comparison of the VHF radar winds to that observed by the AMF radar was prepared. Figure 9 presents the results for the same period and altitude range as shown in Fig. 7. The wind measurements compared in these observations were obtained in SA mode. The wind directions in (b) agree well and the median difference is nearly zero. The wind speed (a) obtained from the VHF radar is nearly double as large as the wind speed observed with the wide-beam AMF radar. The narrow-beam VHF radar has a much smaller beamwidth and a range resolution of ten times less than the AMF radar (see Table 1). In addition, winds were only observed in the presence of PMSE. Furthermore, the atmospheric structures observed by the ALWIN MST radar have a much smaller vertical extension compared to the MF radars because of its Bragg-wavelength of $3 \mathrm{~m}$ ( $75 \mathrm{~m}$ for the AMF radar). The rms difference for the AMF and VHF radar wind speed observations was determined to $25.5 \mathrm{~m} \mathrm{~s}^{-1}$ for $82-86 \mathrm{~km}$ altitude. The rms difference for the directions was estimated to $1.5^{\circ}$. Note, the wide-beam AMF radar and the narrow-beam VHF radar are difficult to compare, often the echoes observed with the VHF radar cover an altitude range considerably more narrow than the pulse width of the AMF radar. 

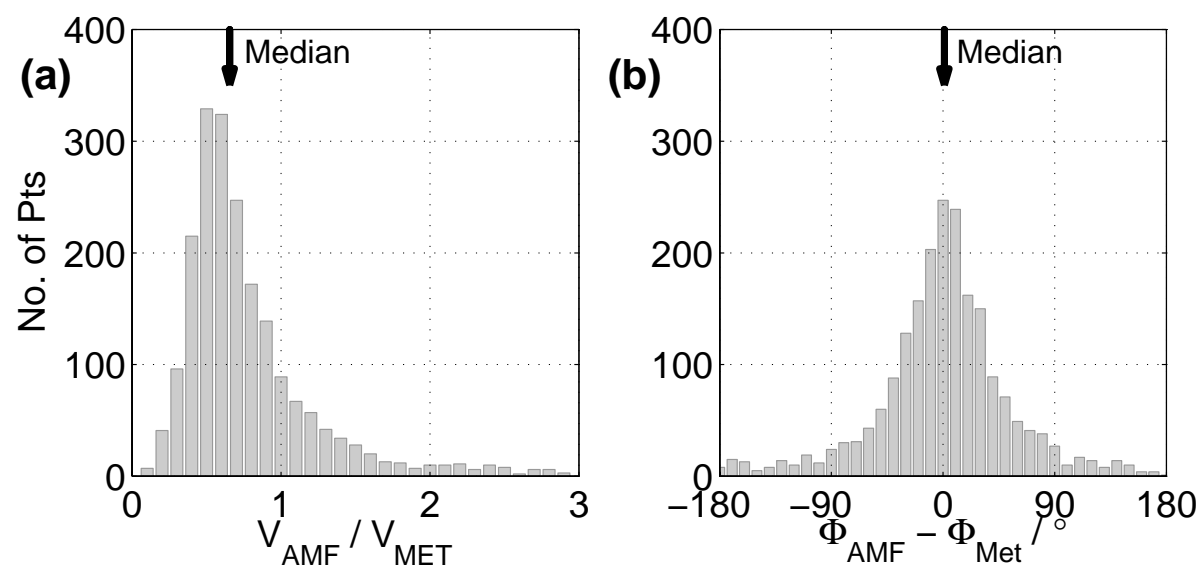

Fig. 10. Histogram of the ratios of the wind speeds (a) and differences of the wind directions (b) between Andenes MF and Andenes Meteor radars in the altitude range of 82 and $86 \mathrm{~km}$ (July 2003).

In principle, the winds derived from meteor radars are estimated in a different way. The transmitted radio wave is reflected at the ionized meteor trail and its radial velocity is determined. From many meteors an hourly mean wind vector is derived by fitting the individual radial velocities. Figure 10 presents the ratios of the wind speed (a) and the differences of the direction (b) between the AMF radar and the meteor radar at altitudes between 82 and $86 \mathrm{~km}$. The directions (shown in b) agree well in this distribution plot but the wind speed (a) of the AMF radar is less than the winds derived from meteor observations in the order of $30 \%$. These results are in good agreement with the observations of Thayaparan et al. (1995), Hocking and Thayaparan (1997), and Manson et al. (2004). The bias and the standard deviations for wind speed and direction are shown in Table 3. The rms differences were also determined for this observation to $12.8 \mathrm{~m} \mathrm{~s}^{-1}$ and to $2.5^{\circ}$ for wind speed and direction, respectively.

\section{Discussion}

At tropospheric altitudes radar winds obtained from DBS and SA experiments were compared to a large number of radiosonde launches at polar latitudes. A high correlation between the radar and radiosonde wind speeds was found for many simultaneous measurements over a period of four years and the height range between 2 and $8 \mathrm{~km}$. The wind speed obtained from DBS measurements show an underestimation of 10\%. Thomas et al. (1997) found in their analysis from several simultaneous measurements a bias of $4-6 \%$ in the altitude range of $4-14 \mathrm{~km}$. The results shown in this comparison fit well to the previous results as mentioned above. The difference between the SA observation and the radiosondes is larger and was determined to about $15 \%$. The wind directions are always represented well by all methods. The bias can be attributed to a certain degree to the spacial inho-
Table 3. Comparison of mesospheric wind estimations between the AMF radar and other available radar instruments using the SA methods (bias, standard deviation, and rms differences).

\begin{tabular}{ccccc}
\hline & & bias & std & $\mathrm{rms}$ \\
\hline \multirow{2}{*}{ AMF - SMF } & $V$ & $-15.5 \mathrm{~m} \mathrm{~s}^{-1}$ & $0.9 \mathrm{~m} \mathrm{~s}^{-1}$ & $15.5 \mathrm{~m} \mathrm{~s}^{-1}$ \\
& $\Phi$ & $6.6^{\circ}$ & $2.4^{\circ}$ & $6.9^{\circ}$ \\
AMF - VHF & $V$ & $-25.5 \mathrm{~m} \mathrm{~s}^{-1}$ & $0.9 \mathrm{~m} \mathrm{~s}^{-1}$ & $25.5 \mathrm{~m} \mathrm{~s}^{-1}$ \\
& $\Phi$ & $1.4^{\circ}$ & $0.7^{\circ}$ & $1.5^{\circ}$ \\
AMF - MET & $V$ & $-12.9 \mathrm{~m} \mathrm{~s}^{-1}$ & $3.3 \mathrm{~m} \mathrm{~s}^{-1}$ & $13.2 \mathrm{~m} \mathrm{~s}^{-1}$ \\
& $\Phi$ & $1.4^{\circ}$ & $1.3^{\circ}$ & $1.8^{\circ}$ \\
\hline
\end{tabular}

mogeneity of the wind field but it can not be quantitatively specified.

At altitudes between 70 and $92 \mathrm{~km}$ radars at frequencies in the MF/HF and VHF band can be used for mesospheric wind measurements as well as falling spheres, chaff clouds, satellite observations, or optical detections. From previous observations it was found that the MF radar winds were smaller than winds obtained from VHF radars (Lübken et al., 1990; Manson et al., 1992). In a comparison shown by Hall et al. (2005) for winds measured by MF and meteor radars located near Troms $\varnothing$, Northern Norway, the authors found an underestimation of the horizontal winds of about $20 \%$ below $91 \mathrm{~km}$. Similar results were shown by Cervera and Reid (1995) for the Australian site where they have analyzed the difference between MF and meteor radar winds. A long term study was presented by Thayaparan and Hocking (2002) and a weak correlation was reported. Manson et al. (1996) and Meek et al. (1997) compared MF radar winds to Fabry-PerotInterferometer observations which matches best at $98 \mathrm{~km}$ altitude. In the comparision of MF radar winds to that obtained from the HRDI instrument on the UARS satellite Meek et al. (1997) found a speed ratio of 0.7 for two altitude layers 
(70-85 km and $85-94 \mathrm{~km}$ ). The speed ratio between the MF radar and the HRDI instrument were in the same order of magnitude than the ratios presented in Fig. 9. However, the measurements were separated by $\sim 3^{\circ}$ in latitude $(370 \mathrm{~km})$ and the differences were explained by a latitude difference in the mean circulation pattern and an earlier occurrence of the tidal oscillation. Na-Doppler lidar winds compared to the MF radar winds show similar results with an rms difference of $20 \mathrm{~m} \mathrm{~s}^{-1}$ for difference-filtered data (Franke et al., 2001).

The results presented here show the comparison of tropospheric and mesospheric wind measurements to in-situ measurements by radiosondes and by falling spheres. Since the in-situ observations have non-uniform height resolutions these data were fitted into height bins comparable to the radar range resolution. The radar wind estimates are, in general, smaller than the in-situ results which was also found in previous studies. Most of the presented data are common volume measurements. These might be influcened by small scale fluctuations due to the orography or due to atmospheric waves to whom the in-situ instruments are very sensitive but the radar observation is an averaged measurement over a larger volume. The more narrow the illuminated volume the smaller are the differences in the wind speeds. The wind directions are always represented very well.

At mesospheric altitudes wind observations from different radars were compared for a representative summer month. This comparison shows that the wind speeds obtained from the narrow-beam Saura MF radar as well as the Alwin MST and the meteor radar are larger by a factor of 1.3 to $1.5 \mathrm{com}-$ pared to the wide-beam Andenes MF radar. This corresponds also to earlier observations (Manson et al., 1992).

In order to understand the differences between the widebeam AMF radar and the narrow-beam SMF radar a comparison of the aspect sensitivity and the spectral width was performed. The spectral width as a measure of velocity fluctuations does not differ very much for the two radars. The atmospheric structures observed by these radars must therefore be nearly identical. The difference in the aspect sensitivity parameter shows an asymmetric distribution with a peak where the aspect sensitivity for the narrow-beam SMF radar is larger. Further studies should clarify the influence of the radar beamwidth on the aspect sensitivity and also on the wind velocity estimated using the SA technique. However, the beam width of the radar contributes most significantly to the difference between AMF and SMF wind speeds because a wide beam with longer pulse width illuminates a larger volume where backscattering will occur.

\section{Summary}

Wind measurements obtained from radars operating at different frequencies as well as winds from balloons and falling spheres were used in this study. They represent the capabilities of the very good facilities near the ALOMAR obser- vatory in Northern Norway. The results illustrate that wind directions are well estimated by the different methods of observation. On the other hand, the radar wind speeds correlate well to balloons and falling spheres but are mostly underestimated. Each radar used in this study estimates wind values characterized by the instrumentally conditioned height and temporal resolution. Furthermore, the radar observations were averaged in time above a localized point whereas the insitu methods are averaged in time-of-flight which is equivalent to an averaging in space. The wide-beam Andenes MF radar observes smaller wind speeds but the measurements are now continuously running for ten years. Here, only the spaced antenna observations of the narrow-beam Saura MF radar were discussed, the Doppler beam steering capability of this narrow-beam radar will be the topic of another paper. The biases, standard deviations, and rms differences between tropospheric wind measurements by radars and in-situ observations by radiosondes were discussed. The spaced antenna radar wind speeds are biased by $-2.9 \mathrm{~m} \mathrm{~s}^{-1}$ with a rms error of $5.0 \mathrm{~m} \mathrm{~s}^{-1}$ and for the Doppler beam swinging wind estimates a bias of $-1.1 \mathrm{~m} \mathrm{~s}^{-1}$ with a rms error of $3.8 \mathrm{~m} \mathrm{~s}^{-1}$ was determined. The wind directions agree well for both methods with a very low bias $\left(-0.5^{\circ}\right.$ for $\mathrm{SA}$ and $-1.6^{\circ}$ for DBS) and a rms error of about $16.5^{\circ}$. Furthermore, these parameters were obtained for the comparison between different radars at mesospheric altitudes. Here, biases of $-15.5 \mathrm{~m} \mathrm{~s}^{-1}$ and $6.6^{\circ}$ with rms errors of $15.5 \mathrm{~m} \mathrm{~s}^{-1}$ and $6.9^{\circ}$ were found for the wind speed and direction comparisons of the narrow-beam Saura MF radar to the wide-beam Andenes MF radar at altitudes between 82 and $86 \mathrm{~km}$. Due to the narrow beamwidth the Saura MF radar provides higher wind speeds than the wide-beam Andenes MF radar. The estimates by comparing meteor radar winds to the Andenes MF radar winds have a bias of $-12.9 \mathrm{~m} \mathrm{~s}^{-1}$ and $1.4^{\circ}$ and a rms error of $-13.2 \mathrm{~m} \mathrm{~s}^{-1}$ and $1.8^{\circ}$. Furthermore, the wind measurements obtained from the VHF radar are larger than that from the Andenes MF radar with rms errors determined to $25.5 \mathrm{~m} \mathrm{~s}^{-1}$ and $1.5^{\circ}$ for wind speed and direction, respectively. From wind measurements obtained by the wide-beam $2 \mathrm{MHz}$ radar comes out that wind speeds are lower by about $35 \%$ compared to insitu observations by falling spheres and for the narrow-beam $3 \mathrm{MHz}$ radar the wind speed is underestimated by about $20 \%$. The smaller beamwidth of the Saura MF radar leads to larger wind velocities.

\section{Appendix A}

\section{Determination of bias, standard deviations and root mean squares}

The bias determines the mean deviation and reflects the systematic error of the measurement:

$\Delta_{\text {bias }}=\frac{1}{N} \sum_{i=1}^{N}\left|V_{i}^{\mathrm{radar}}-V_{i}^{\mathrm{RS}}\right|$. 
The standard deviation determines the statistical error of the measurement:

$\Delta_{\text {std }}=\sqrt{\frac{1}{N-1} \sum_{i=1}^{N}\left(\left|V_{i}^{\text {radar }}-V_{i}^{\mathrm{RS}}\right|-\Delta_{\text {bias }}\right)^{2}}$.

The root mean square error is used to determine the total error of the measurement:

$\Delta_{\mathrm{rms}}=\sqrt{\frac{1}{N} \sum_{i=1}^{N}\left|V_{i}^{\mathrm{radar}}-V_{i}^{\mathrm{RS}}\right|^{2}}$.

\section{Appendix B}

\section{Determination of aspect sensitivity and the spectral width from SA radar measurements}

The aspect sensitivity describes the angular dependence of the scatterers as pointed out by several authors (e.g. Röttger, 1981; Hocking et al., 1986; Lesicar and Hocking, 1992; Hocking and Hamza, 1997). Quantitatively, the aspect sensitivity $\theta_{s}$ can be derived from the spaced antenna experiment using the relation

$\frac{1}{\sin ^{2} \theta_{s}}=\frac{1}{\sin ^{2} \theta_{s b}}-\frac{1}{\sin ^{2} \theta_{b}}$,

where $\theta_{b}$ is the two-way $1 / e$-width of polar diagram of the radar beam and $\theta_{s b}$ the $1 / e$-width of the effective polar diagram (Lesicar and Hocking, 1992). Using the "spacial correlation" method (Lesicar and Hocking, 1992) the effective polar diagram $\theta_{s b}$ can be determined from

$\theta_{s b}=\frac{15.2 \lambda \sqrt{R_{a x}}}{S_{0.5}}$,

with $R_{a x}=r_{\text {maj }} / r_{\text {min }}$ the axial ratio between the major and the minor axis of the correlation ellipse, $S_{0.5}=\sqrt{r_{\text {maj }} r_{\text {min }}}$ the pattern scale, and $\lambda$ the radar wavelength.

The spectral width can be derived from the fading time $T_{0.5}$ in the frame of the ground diffraction pattern (Briggs, 1980) as given with

$\sigma=\frac{\lambda \sqrt{\ln 2}}{4 \pi T_{0.5}}$.

Acknowledgements. The authors thank the staff from the ALOMAR Observatory and the Andøya Rocket Range for maintaining the radar operation, providing radiosonde data, and support the rocket campaigns as well as the members of the DLR Mobile Raketenbasis. The authors also thank F.-J. Lübken for providing falling sphere profiles and for valuable discussions. The project was partly funded by the European Research Council under the contract RITA-CT-2003-506208. The authors thank the referees for their valuable comments.

Topical Editor U.-P. Hoppe thanks two anonymous referees for their help in evaluating this paper.

\section{References}

Briggs, B. H.: Radar observations of atmospheric winds and turbulence: A comparison of techniques, J. Atmos. Terr. Phys., 42, 823-833, 1980.

Briggs, B. H.: The Analysis of Spaced Sensor Records by Correlation Techniques, in: Middle Atmosphere Program, edited by: Vincent, R., vol. 13 of Handbook for MAP, pp. 166-186, 1984.

Burrage, M. D., Skinner, W. R., Gell, D. A., Hays, P. B., Marshall, A. R., Ortland, D. A., Manson, A. H., Franke, S. J., Fritts, D. C., Hoffmann, P., McLandress, C., Niciejewski, R., Schmidlin, F. J., Shepherd, G. G., Singer, W., Tsuda, T., and Vincent, R. A.: Validation of mesosphere and lower thermosphere winds from high resolution Doppler imager on UARS, J. Geophys. Res., 101, 10365-10 392, 1996.

Cervera, M. A. and Reid, I. M.: Comparison of simultaneous wind measurements using colocated VHF meteor radar and MF spaced antenna radar systems, Radio Sci., 30, 95RS00644, 1995.

Clark, R. R., Tate, R. J., Salah, J. E., and Goncharenko, L. P.: Common-volume measurements of mesospheric winds using radar and optical instruments: 2. Small scale structure implications, J. Atmos. Solar-Terr. Phys., 61, 1273-1287, 1999.

Franke, S. J., Stoll, E., States, R. J., and Gardner, C. S.: Comparison of Na Doppler lidar and MF radar measurements of meridional windsin the mesosphere above Urbana, Il, J. Atmos. Solar-Terr. Phys., 63, 1789-1796, 2001.

Hall, C., Aso, T., Tsutsumi, M., Nozawa, S., Manson, A., and Meek, C.: A comparison of mesosphere and lower thermosphere neutral winds as determined by meteor and medium-frequency radar at $70^{\circ} \mathrm{N}$, Radio Sci., 40, RS4001, doi:10.1029/2004RS003102, 2005.

Hines, C., Adams, G., Brosnahan, J., Djuth, F., Sulzer, M., Tepley, C., and Van Baelen, J.: Multi-instrument observations of mesospheric motions over Arecibo: comparisons and interpretations, J. Atmos. Terr. Phys., 55, 241-287, 1993.

Hocking, W. K.: On the extraction of atmospheric turbulence parameters from radar backscatter Doppler spectra - I. Theory, J. Atmos. Terr. Phys., 45, 89-102, 1983a.

Hocking, W. K.: Mesospheric turbulence intensities measured with HF radar at $35^{\circ} \mathrm{S}-$ II, J. Atmos. Terr. Phys., 45, 103-114, 1983b.

Hocking, W. K.: Two years of continuous measurements of turbulence parameters in the upper mesosphere and lower thermosphere made with a 2-MHz radar, J. Geophys. Res., 93, 24752491, 1988.

Hocking, W. K.: Middle atmosphere program, vol. 30, chap. Target parameter estimation, pp. 228-268, Handbook for MAP, 1989.

Hocking, W. K.: System design, signal-processing procedures, and preliminary results for the Canadian (London, Ontario) VHF atmospheric radar, Radio Sci., 32, 687-706, 1997.

Hocking, W. K. and Hamza, A. M.: A quantitative measure of the degree of anisotropy of turbulence in terms of atmospheric parameters, with particular relevance to radar studies, J. Atmos. Solar-Terr. Phys., 59, 1011-1020, 1997.

Hocking, W. K. and Thayaparan, T.: Simultaneous and colocated observations of winds and tides by MF and meteor radars over London, Canada $\left(43^{\circ} \mathrm{N}, 81^{\circ} \mathrm{W}\right)$, during 1994-1996, Radio Sci., 32, 96RS03467, 1997.

Hocking, W. K., Rüster, R., and Czechowsky, P.: Absolute reflectivities and aspect sensitivities of VHF radio wave scatterers measured with the SOUSY radar, J. Atmos. Terr. Phys., 48, 131-144, 
1986.

Hocking, W. K., Fuller, B., and Vandepeer, B.: Real-time determination of meteor-related parameters utilizing modern digital technology, J. Atmos. Solar-Terr. Phys., 63, 155-169, 2001.

Holdsworth, D. A.: Influence of instrumental effects upon the full correlation analysis, Radio Sci., 34, 643-655, 1999.

Holdsworth, D. A. and Reid, I. M.: The Buckland Park MF radar: routine observation scheme and velocity comparisons, Ann. Geophys., 22, 3815-3828, 2004a,

http://www.ann-geophys.net/22/3815/2004/.

Holdsworth, D. A. and Reid, I. M.: Comparisons of full correlation analysis (FCA) and imaging Doppler interferometry (IDI) winds using the Buckland Park MF radar, Ann. Geophys., 22, 38293842, 2004b,

http://www.ann-geophys.net/22/3829/2004/.

Holdsworth, D. A., Vincent, R. A., and Reid, I. M.: Mesospheric turbulent velocity estimation using the Buckland Park MF radar, Ann. Geophys., 19, 1007-1017, 2001, http://www.ann-geophys.net/19/1007/2001/.

Kato, S., Tsuda, T., Yamamoto, M., Sato, T., and Fukao, S.: First results obtained with a middle and upper atmosphere (MU) radar, J. Atmos. Terr. Phys., 48, 1259-1267, 1986.

Latteck, R., Singer, W., and Bardey, H.: The Alwin MST radar technical design and performances, in: Proc. 14th ESA Symp. on European Rocket and Ballon Programmes and related Research, edited by: Kaldeich-Schürmann, B., vol. ESA SP-437, pp. 179$184,1999$.

Lesicar, D. and Hocking, W.: Studies of seasonal behaviour of the shape of mesosperic scatterers using a $1.98 \mathrm{MHz}$ radar, J. Atmos. Terr. Phys., 54, 295-309, 1992.

Liu, A., Hocking, W., Franke, S., and Thayaparan, T.: Comparison of Na lidar and meteor radar wind measurements at Starfire Optical Range, NM, USA, J. Atmos. Solar-Terr. Phys., 64, 31-40, 2002.

Lübken, F.-J., von Zahn, U., Manson, A., Meek, C., Hoppe, U.-P., Schimdlin, F. J., Stegman, J., Murtagh, D. P., Rüster, R., Schmidt, G., Widdel, H.-U., and Espy, P.: Mean state densities, temperatures and winds during the MAC/SINE and MAC/EPSILON campaigns, J. Atmos. Terr. Phys., 52, 955-970, 1990.

Luce, H., Fukao, S., Yamamoto, M., Sidi, C., and Dalaudier, F.: Validation of winds measured by MU radar with GPS radiosondes during the MUTSI campaign, J. Atmos. Ocean. Techn., 18, 817-829, 2001.

Manson, A., Meek, C., Brekke, A., and Moen, J.: Mesosphere and lower thermosphere $(80-120 \mathrm{~km})$ winds and tides from near Tromso $\left(70^{\circ} \mathrm{N}, 19^{\circ} \mathrm{E}\right)$ : comparison between radars (MF, EISCAT, VHF) and rockets, J. Atmos. Terr. Phys., 54, 927-950, 1992.

Manson, A., Yi, F., Hall, G., and Meek, C.: Comparison between instantaneous wind measurements made at Saskatoon (52N, $107 \mathrm{~W})$ using the colocated medium frequency radars and FabryPerot interferometer instruments: Climatology (1988-1992) and case studies, J. Geophys. Res., 101, 29 553-29 563, 1996.

Manson, A., Meek, C., Hall, C., Nozawa, S., Mitchell, N., Pancheva, D., Singer, W., and Hoffmann, P.: Mesopause dynamics from the scandinavian triangle of radars within the PSMOSDATAR Project, Ann. Geophys., 22, 367-386, 2004, http://www.ann-geophys.net/22/367/2004/.
Meek, C. and Manson, A.: Combination of Primrose Lake $\left(54^{\circ} \mathrm{N}\right.$, $\left.110^{\circ} \mathrm{W}\right)$ ROCOB winds $(20-60 \mathrm{~km})$ and Saskatoon $\left(52^{\circ} \mathrm{N}\right.$, $\left.107^{\circ} \mathrm{W}\right) \mathrm{MF}$ radar winds (60-110 km), J. Atmos. Terr. Phys., 47, 477-487, 1985.

Meek, C., Manson, A., Burrage, M., Garbe, G., and Cogger, L.: Comparisons between Canadian prairie MF radars, FPI (green and $\mathrm{OH}$ lines) and UARS HRDI systems, Ann. Geophys., 15, 1099-1110, 1997, http://www.ann-geophys.net/15/1099/1997/.

Meek, C. E. and Reid, I. M.: Middle atmosphere program, vol. 14, chap. A simple model for testing the effects of gravitywave-produced vertical oscillations of scattering irregularities on spaced-antenna, horizontal drift measurements, pp. 131-133, Handbook for MAP, 1989.

Müllemann, A.: Temperaturen, Winde und Turbulenz in der polaren Sommermesosphäre, Ph.D. thesis, Univ. Rostock, 2004.

Müllemann, A. and Lübken, F.-J.: Horizontal winds in the mesosphere at high latitudes, Adv. Space Res., 35, 1890-1894, doi: 10.1016/j.asr.2004.11.014, 2005.

Murayama, Y., Igarashi, K., Nishimuta, I., Yamazaki, R., Oyama, K.-I., Tsuda, T., Nakamura, T., Fukao, S., Widdel, H.-U., and Schlegel, K.: Cooperative wind observation in the upper mesosphere and lower thermosphere with foil chaff technique, the MU radar, and Yamagawa MF radar, Earth Plan. Space, 51, 719-729, 1999.

Reid, I. M.: MF Doppler and spaced antenna radar measurements of upper middle atmosphere winds, J. Atmos. Terr. Phys., 50, 117-134, 1988.

Reid, I. M.: Radar observtions of stratified layers in the mesosphere and lower thermosphere (50-100 km), Adv. Space Res., 10, 719, 1990.

Röttger, J.: Investigations of lower and middle atmosphere dynamics with spaced antenna drifts radars, J. Atmos. Terr. Phys., 43, 277-292, 1981.

Röttger, J., Czechowsky, P., and Schmidt, G.: First low-power VHF radar observations of tropospheric, stratospheric, and mesospheric winds and turbulence at the Arecibo Observatory, J. Atmos. Terr. Phys., 43, 789-800, 1981.

Salah, J., Goncharenko, L., Sipler, D., Clark, R., and Tate, R.: Common-volume measurements of mesospheric winds using radar and optical instruments: 1. Comparison of observations, J. Atmos. Solar-Terr. Phys., 61, 1259-1271, 1999.

Singer, W., Keuer, D., and Eriksen, W.: The Alomar MF radar: Technical design and first results, in: In Proc. 13th ESA Symposium on European Rocket and Balloon Programes and Related Research, edited by: Kaldeich-Schürmann, B., vol. ESA SP-397, pp. 101-104, 1997.

Singer, W., Bremer, J., Hocking, W., Weiss, J., Latteck, R., and Zecha, M.: Temperature and wind tides around the summer mesopause at middle and arctic latitudes, Adv. Space Res., 31, 2055-2060, 2003a.

Singer, W., Latteck, R., Holdsworth, D., and Kristiansen, T.: A new narrow beam $\mathrm{MF}$ radar at $3 \mathrm{MHz}$ for studies of the high-latitude middle atmosphere: System description and first results, in: Proceedings of the Tenth International Workshop on Technical and Scientific Aspects of MST Radar (MST10), edited by: Cho, J., Lau, J., and Röttger, J., vol. SCOSTEP Secret., pp. 385-390, Radio Observatorio de Jicamarca, Lima, Peru, Pirua, Peru, 13-20. Mai 2003, 2003b. 
Singer, W., Latteck, R., and Holdsworth, D.: A new narrow beam Doppler radar at $3 \mathrm{MHz}$ for studies of the high-latitude middle atmosphere, Adv. Space Res., 41, 1488-1494, doi:10.1016/j.asr. 2007.10.006, 2008.

Thayaparan, T. and Hocking, W.: A long-term comparison of winds and tides measured at London, Canada $\left(43^{\circ} \mathrm{N}, 81^{\circ} \mathrm{W}\right)$ by colocated MF and meteor radars during 1994-1999, J. Atmos. Solar-Terr. Phys., 64, 931-946, 2002.

Thayaparan, T., Hocking, W., and MacDougall, J.: Middle atmospheric winds and tides over London, Canada $\left(43^{\circ} \mathrm{N}, 81^{\circ} \mathrm{W}\right)$ during 1992-1993, Radio Sci., 30, 95RS00803, 1995.

Thomas, L., Astin, I., and Worthington, R.: A statistical study of underestimates of wind speeds by VHF radar, Ann. Geophys., 15, 805-812, 1997, http://www.ann-geophys.net/15/805/1997/.

Vandepeer, B. G. W. and Hocking, W. K.: A comparison of Doppler and spaced antenna radar techniques for the measurement of turbulent energy dissipation rates, Geophys. Res. Lett., 20, 17-20, 1993.
Venkat Ratnam, M., Narayana Rao, D., Narayana Rao, T., Thulasiraman, S., Nee, J., Gurubaran, S., and Rajaram, R.: Mean winds observed with Indian MST radar over tropical mesosphere and comparison with various techniques, Ann. Geophys., 19, 10271038, 2001, http://www.ann-geophys.net/19/1027/2001/.

Vincent, R., May, P., Hocking, W., Elford, W., Candy, B., and Briggs, B.: First results with the Adelaide VHF radar: spaced antenna studies of tropospheric winds, J. Atmos. Terr. Phys., 49, 353-366, 1987.

Vincent, R. A., Stubbs, T. J., Pearson, P. H. O., Lloyd, K. H., and Low, C. H.: A comparison of partial reflection drifts with winds determined by rocket techniques-1, J. Atmos. Terr. Phys., 39, 813-821, 1977.

Weber, B. and Wuertz, D.: Comparison of rawinsonde and wind profiler radar measurements, J. Atmos. Ocean. Techn., 7, 157174, 1990. 